\title{
GRADED COATINGS FOR METALLIC IMPLANT ALLOYS
}

\author{
Eduardo Saiz and Antoni P. Tomsia \\ Lawrence Berkeley National Laboratory \\ Berkeley, CA 94720 \\ USA
}

Jose M. Gomez-Vega

Nagoya University

Furo-Cho, Chikkusa-ku, Nagoya 464-8603

Japan
Shigeru Fujino

Kyushu University, Kasuga-shi, Fukuoka 816-8580

Japan

\begin{abstract}
Graded glass and glass-hydroxyapatite coatings on Ti-based and $\mathrm{Co}-\mathrm{Cr}$ alloys have been prepared using a simple enameling technique. The composition of the glasses has been tailored to match the thermal expansion of the alloys. By controlling the firing time, and temperature, it has been possible to control the reactivity between the glass and the alloy and to fabricate coatings (25 to $150 \mu \mathrm{m}$ thick) with excellent adhesion to the substrate, resistant to corrosion and able to precipitate hydroxyapatite during in vitro tests in simulated body fluid.
\end{abstract}

\section{INTRODUCTION}

Metals such as 316L stainless steel, Co-Cr or Ti alloys are widely used for skeletal repair. ${ }^{1-3}$ However, one of the main drawbacks of using metallic implants is that they are bioinert and become encapsulated by dense fibrous tissue inside the body. ${ }^{3}$ This impedes proper stress distribution at the implant-bone interface, which can result in an interfacial failure and loosening of the implant, with the possible consequence of fracture in the adjacent bone. ${ }^{3,4}$ Therefore, a coating that enhances the adherence of the metal to the bone and protects the alloy from corrosion by the body fluids will accelerate the stabilization of the implant and extend its duration.

Coatings of hydroxyapatite (HA) fabricated by plasma spraying have been extensively investigated, ${ }^{3,5-6}$ although there are several critical problems 
associated with the degradation of HA due to the elevated temperature required in the process, and lack of strength at the metal/HA interface. ${ }^{7-9}$ An alternative method is to coat the implant with a bioactive glass (able to form HA in vivo) that could provide the desired interfacial attachment to the bone. Several groups have attempted to coat metallic implants with bioactive glasses using enameling, rapid immersion in molten glass, or plasma-spraying techniques. ${ }^{10-13}$ Although some coatings with excellent in vitro behavior have been obtained, most of the glass coatings are marred by cracking and poor reliability at the glass/metal interface. ${ }^{10,12}$ In many cases glass/metal reactions lead to the formation of brittle interfacial layers and gas bubbles in the coating. ${ }^{14,15}$

It has been suggested that future progress in biomaterials must include the development of coatings with programmed dissolution of multilayer surfaces. ${ }^{16}$ Such surfaces would provide new opportunities to optimize the biomaterial coating surface for different periods of the healing-in phase. This programmed dissolution can then be used to expose different micro-architectures, chemical patterns, and porosities at various times. Fabrication of coatings for medical applications involves a compromise between adhesion, mechanical stability, and bioactivity, but coatings that satisfy all these requirements are extremely difficult to develop. The aim of this work is to use a simple enameling technique to fabricate graded glass and glass-hydroxyapatite coatings on $\mathrm{Co}-\mathrm{Cr}$ and Ti-based alloys that will combine good adhesion to the metal with rapid biofixation and long- term stability.

\section{EXPERIMENTAL}

Glasses in the system $\mathrm{SiO}_{2}-\mathrm{Na}_{2} \mathrm{O}-\mathrm{K}_{2} \mathrm{O}-\mathrm{CaO}-\mathrm{MgO}-\mathrm{P}_{2} \mathrm{O}_{5}$ (Table I) were prepared by mixing $\mathrm{SiO}_{2}(99.5 \%)^{*}, \mathrm{CaCO}_{3}(99.9 \%)^{* *}, \mathrm{MgO}(98.6 \%)^{* *}, \mathrm{~K}_{2} \mathrm{CO}_{3}$ $(99 \%)^{\#}, \mathrm{NaHCO}_{3}(99.5 \%)$ and $\mathrm{NaPO}_{3}(99.7 \%)^{\#}$ using a high-speed stirrer. The mixture was dried at $80^{\circ} \mathrm{C}$ for 12 hours and then fired in air at $1400^{\circ} \mathrm{C}$ for 4 hours in a $\mathrm{Pt}$ crucible. The melt was cast into a graphite mold to obtain glass plates $(\sim 50 \times 50 \times 5 \mathrm{~mm})$ that were subsequently annealed at $500^{\circ} \mathrm{C}$ for 6 hours to relieve stresses. The thermal expansion $(\alpha)$, softening $\left(\mathrm{T}_{\mathrm{s}}\right)$ and transformation $\left(\mathrm{T}_{\mathrm{g}}\right)$ temperatures were measured in a calibrated dilatometer with an alumina holder and push rod, using glass bars $25 \mathrm{~mm}$ long.

\footnotetext{
${ }^{*}$ Cerac, USA.

** JT Baker, USA.

*** JT Baker, USA.

\#Allied Chemical, USA

** JT Baker, USA.
} 
To manufacture the coatings, the glass was milled in a planetary agate mill, and a suspension of the glass powder (particle size $<20 \mu \mathrm{m}$ ) in ethanol was deposited on the metallic substrates (Ti, Ti6Al4V or Vitallium ${ }^{\circledR}$ a Co-Cr alloy), which had been previously polished with diamond (1 $\mu \mathrm{m}$ particle size) and cleaned in acetone and ethanol. The resulting coatings were dried in air at $75^{\circ} \mathrm{C}$ for 12 hours and fired in air or $\mathrm{N}_{2}$ at temperatures ranging between 650 to $850^{\circ} \mathrm{C}$ in order to make the glass flow and adhere to the metal. For the firings in air, the specimens were introduced in the furnace previously preheated to $600-650^{\circ} \mathrm{C}$ and heated at $40^{\circ} \mathrm{C} / \mathrm{min}$ to the desired temperature. During heating, the furnace was evacuated to $0.1 \mathrm{~atm}$. Once the maximum temperature was reached, air was let into the chamber. After the required time, they were quenched in air. Graded coatings have been manufactured by depositing two or three different glass or glass-HA layers on the metal substrates using the previously described method following by firing in air or $\mathrm{N}_{2}$. The final coating thickness ranged between 25 to $150 \mu \mathrm{m}$.

Table I. Glass compositions

\begin{tabular}{|c|c|c|c|c|c|c|}
\hline & $\mathrm{SiO}_{2}$ & $\mathrm{Na}_{2} \mathrm{O}$ & $\mathrm{K}_{2} \mathrm{O}$ & $\mathrm{CaO}$ & $\mathrm{MgO}$ & $\mathrm{P}_{2} \mathrm{O}_{5}$ \\
\hline Bioglass $^{\circledR}$ & 45.0 & 24.5 & & 24.5 & & 6.0 \\
\hline 6P44-a & 44.2 & 23.6 & 6.5 & 12.6 & 7.1 & 6.0 \\
\hline 6P44-b & 44.2 & 17.0 & 4.6 & 18.0 & 10.2 & 6.0 \\
\hline 6P44-c & 44.2 & 10.3 & 2.8 & 23.4 & 13.3 & 6.0 \\
\hline 6P50 & 49.8 & 15.5 & 4.2 & 15.6 & 8.9 & 6.0 \\
\hline 6P53-a & 52.7 & 17.0 & 4.6 & 12.6 & 7.1 & 6.0 \\
\hline 6P53-b & 52.7 & 10.3 & 2.8 & 18.0 & 10.2 & 6.0 \\
\hline 6P55 & 54.5 & 12.0 & 4.0 & 15.0 & 8.5 & 6.0 \\
\hline 6P57 & 56.5 & 11.0 & 3.0 & 15.0 & 8.5 & 6.0 \\
\hline 6P61 & 61.1 & 10.3 & 2.8 & 12.6 & 7.2 & 6.0 \\
\hline 6P64 & 64.1 & 9.8 & 2.7 & 11.1 & 6.3 & 6.0 \\
\hline 6P68 & 67.7 & 8.3 & 2.2 & 10.1 & 5.7 & 6.0 \\
\hline
\end{tabular}

The crystallization of the coatings was evaluated by x-ray diffraction (XRD). The surfaces of the coatings, as well as polished cross sections, were examined by optical microscopy and scanning electron microscopy with 
associated energy dispersive spectroscopy analysis (SEM-EDS). The glass metalinterfaces were also analyzed using high resolution transmission electron microscopy (HRTEM).

In order to study the adherence of the coatings, the relative crack resistance was qualitatively evaluated by indentation. Vickers indentations on the coating surfaces were performed in air, with loads up to $6.2 \mathrm{Kg}$. Indentations on the coatings and glass/metal interfaces were also performed on polished cross sections, using loads ranging from 0.05 to $1.2 \mathrm{Kg}$.

Table II. Thermal properties of the metals and glasses $\left(\mathrm{T}_{\mathrm{g}}\right.$ and $\mathrm{T}_{\mathrm{s}}$ are the transformation and softening points, respectively).

\begin{tabular}{|l|c|c|c|}
\hline & $\alpha^{*}\left(10^{-6}{ }^{\circ} \mathrm{C}^{-1}\right)$ & $\mathrm{T}_{\mathrm{g}}\left({ }^{\circ} \mathrm{C}\right)$ & $\mathrm{T}_{\mathrm{s}}\left({ }^{\circ} \mathrm{C}\right)$ \\
\hline Ti & $\sim 9.6$ & & \\
\hline Ti6A14V & $9.1-9.8$ & & \\
\hline Vitallium $^{\circledR}$ & $\sim 14.0$ & & \\
\hline Bioglass $^{\circledR}$ & 15.1 & 511 & 557 \\
\hline 6P44-a & 15.6 & 449 & 503 \\
\hline 6P44-b & 13.0 & 516 & 560 \\
\hline 6P44-c & 11.3 & 527 & 599 \\
\hline 6P50 & 12.2 & 522 & 560 \\
\hline 6P53-a & 12.9 & 530 & 565 \\
\hline 6P53-b & 11.5 & 531 & 608 \\
\hline 6P55 & 11.0 & 548 & 602 \\
\hline 6P57 & 10.8 & 557 & 609 \\
\hline 6P61 & 10.2 & 564 & 624 \\
\hline 6P64 & 9.1 & 565 & 622 \\
\hline 6P68 & 8.8 & 565 & 644 \\
\hline
\end{tabular}

*Measured between 200 and $400^{\circ} \mathrm{C}$

The behavior of selected glass coatings in simulated body fluid (SBF) was studied by in vitro tests. The specimens $(15 \times 10 \times 1 \mathrm{~mm})$ were soaked in $20 \mathrm{ml}$ of $\mathrm{SBF}$ at a constant temperature of $36.5^{\circ} \mathrm{C}$ for times up to 30 days. After soaking, 
the coatings were rinsed in distilled water, dried, and analyzed by XRD, SEMEDS and Fourier Transform Infrared Spectromicroscopy (FTIRSM) in the Advanced Light Source (ALS) at Lawrence Berkeley National Laboratory.

\section{RESULTS AND DISCUSSION}

Table II shows the thermal properties of the fabricated glasses. As expected, an increase in $\mathrm{SiO}_{2}$ and $\mathrm{MgO}$ contents reduces $\alpha$ and increases $\mathrm{T}_{\mathrm{g}}$ and $\mathrm{T}_{\mathrm{s}}$. The softening temperature of all glasses is well below the $\alpha \rightarrow \beta$ transformation temperature of $\mathrm{Ti}\left(955-1010^{\circ} \mathrm{C}\right)$. XRD analysis of the synthesized glasses did not show any crystalline phase with the exception of 6P68, where sodium calcium phosphate $\left(2.4 \mathrm{CaO} \cdot 0.6 \mathrm{Na}_{2} \mathrm{O} \cdot \mathrm{P}_{2} \mathrm{O}_{5}\right)$ crystals were found.

Attempts to fabricate coatings with glasses 6P44-a 6P44-b, 6P53-a as well as the original Bioglass ${ }^{\circledR}$ composition developed by Hench always failed. Due to their hygroscopic nature caused by their high alkaline content (over $20 \mathrm{wt} \%$ ) and the resultant presence of $\left[\mathrm{OH}^{-}\right]$ions on the surface of the glass powders, these glasses crystallize readily close to their flow temperature. Consequently these coatings crystallized almost completely even at the lowest firing temperatures $\left(700^{\circ} \mathrm{C}\right)$, resulting in poor densification and lack of adhesion to the metal. The main crystalline phase present in the Bioglass ${ }^{\circledR}$ coatings was sodium calcium silicate $\left(\mathrm{Na}_{2} \mathrm{Ca}_{2} \mathrm{Si}_{3} \mathrm{O}_{9}\right)$.

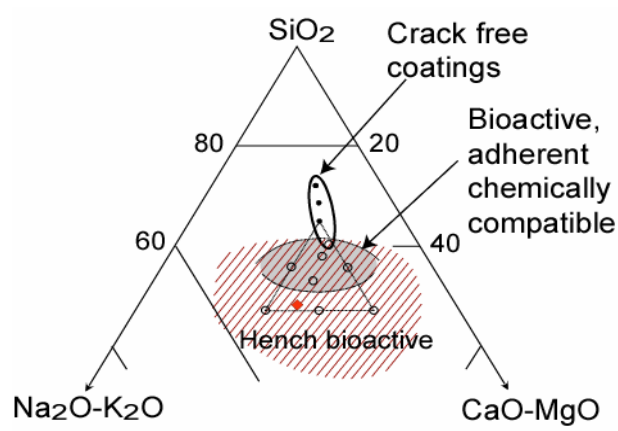

Ti, Ti6Al4V

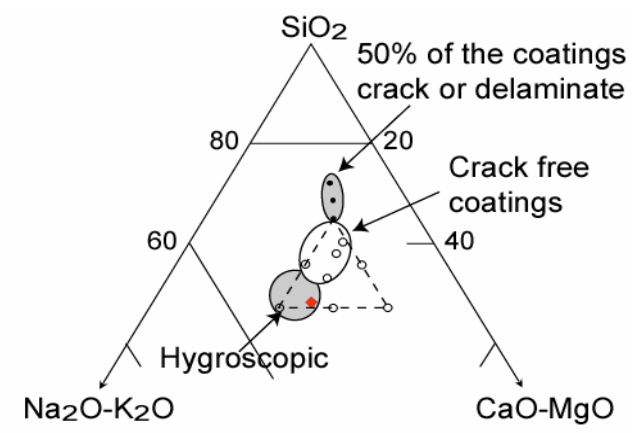

Co-Cr

Figure 1. Behavior of single layer glass coatings on the different metallic alloys. All glass compositions have a constant $6 \mathrm{wt} \% \mathrm{P}_{2} \mathrm{O}_{5}$ content.

Due to the difference in thermal expansion coefficient between the glass and the alloy, thermal stresses are generated in the coating during fabrication that can result in cracking and/or delamination. Figure 1 shows the range of glass compositions that can be used to prepare dense coatings that do not crack or delaminate on $\mathrm{Ti}$ and Ti6Al4V or Co-Cr alloys. Glasses with lower silica content 
have larger thermal expansion and can be used to coat $\mathrm{Co}-\mathrm{Cr}$, whereas $\mathrm{SiO}_{2}$-rich glasses should be used to coat Ti-based alloys.

Similar results are obtained after firing in air or $\mathrm{N}_{2}$, as an example, the effect of firing time and temperature on 6P57 coatings on Ti6A14V and 6P50 on Co-Cr calcined in air is illustrated in Figure 2. Four regions can be distinguished. Below a critical time and temperature, the glass does not sinter. Then, at higher temperatures, the glass flows and forms a dense layer. Some of these coatings undergo delamination when a $6.2 \mathrm{Kg}$ Vickers indentation is applied on the top surface. Nevertheless, a time and temperature region exists where the coatings are dense, exhibit good adhesion, and do not delaminate under indentation tests. In indentations performed at the glass/metal interface on polished cross sections of these coatings, cracks do not propagate along the interface, but rather tend to be driven into the glass (Figure 3). At longer times and temperatures, excessive reaction between the glass and the metal generates brittle reaction layers and/or gas bubbles at the interface, which result in porous coatings and poor adhesion to the substrate. Typically, slightly longer firings can be used in $\mathrm{N}_{2}$ than in air to fabricate coatings with optimum adhesion.
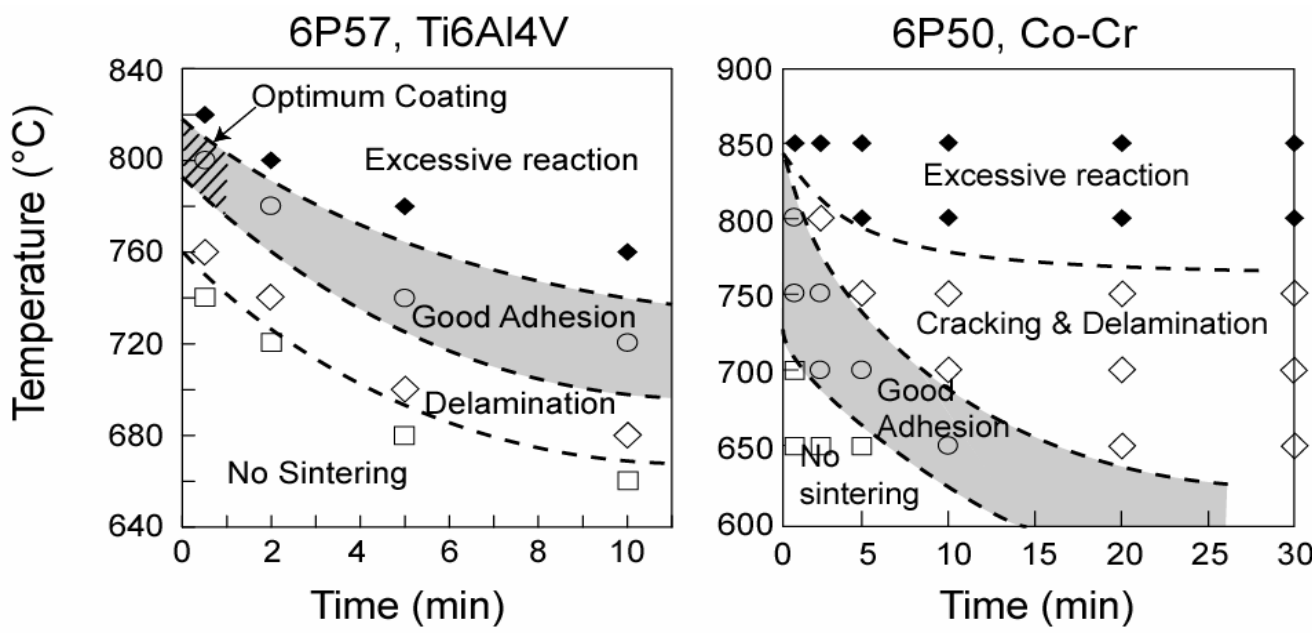

Figure 2. Influence of firing time and temperature on the adhesion of coatings manufactured with glass 6P57 on Ti6A14V and glass 6P50 on Co-Cr (all the coatings were fired in air).

In the coatings with optimum adhesion on $\mathrm{Ti}$ or $\mathrm{Co}-\mathrm{Cr}$ alloys, i.e., those that did not delaminate during indentation, it was not possible to detect any interfacial layer or change in the glass composition using SEM-EDS. However, a TEM image of the glass $6 \mathrm{P} 57 / \mathrm{Ti} 6 \mathrm{~A} 14 \mathrm{~V}$ interface annealed at $800^{\circ} \mathrm{C}$ for 30 seconds showed an interfacial $\mathrm{Ti}_{5} \mathrm{Si}_{3}$ layer $\sim 150 \mathrm{~nm}$ thick (Figure 4). The layer 
was divided into two regions: a continuous nanocrystalline layer in contact with the alloy and, on top of it, a zone with isolated $\mathrm{Ti}_{5} \mathrm{Si}_{3}$ nanoparticles dispersed in the glass. The appearance of isolated particles on the TEM image can also result from the growth of elongated silicide grains, or dendrites, from the continuous layer into the glass. These dendrites may appear as isolated particles wherever they intersect the cross section. At the $\mathrm{Ti}_{5} \mathrm{Si}_{3} /$ alloy interface the lattice fringes of Ti $\{100\}$ and $\mathrm{Ti}_{5} \mathrm{Si}_{3}\{121\}$ were visible. A good lattice match exists between them, which can help in obtaining good adhesion. The SEM-EDS analysis of the cross section of a $6 \mathrm{P} 50$ coating on $\mathrm{Co}-\mathrm{Cr}$ fired at $800{ }^{\circ} \mathrm{C}$ for $30 \mathrm{~min}$ showed the presence of a thin $\mathrm{CrO}_{\mathrm{x}}$ interfacial layer that promoted delamination of the coating.

Figure 3. Vickers indentation at the glass $6 \mathrm{P} 57 / \mathrm{Ti} 6 \mathrm{~A} 14 \mathrm{~V}$ interface (fired at $800^{\circ} \mathrm{C}$ for $30 \mathrm{~s}$ ) using 1.2 $\mathrm{Kg}$ load in ambient air. The cracks were driven towards the glass and the coating did not delaminate.

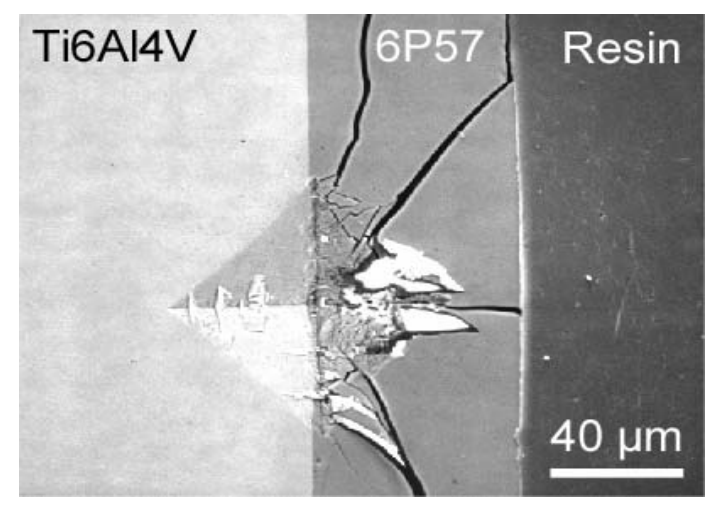

The following sequence of steps can be proposed for the coatings fired in air. During heating, gas flows easily through the porous deposited coating and forms an oxide layer on the alloy surface. When the glass softens and flows, it starts to dissolve the oxides and, once they have been completely dissolved, redox reactions can occur at the glass/metal interface. According to the interfacial analysis, the main reaction for the coatings on Ti-based alloys is the formation of $\mathrm{Ti}_{5} \mathrm{Si}_{3}$, whereas for coatings on Co-Cr alloys is the formation of chromium oxide, according to ${ }^{14}$ :

$$
\begin{aligned}
& 8 \mathrm{Ti}+3 \mathrm{SiO}_{2}\{\text { glass }\} \rightarrow \mathrm{Ti}_{5} \mathrm{Si}_{3}+3 \mathrm{TiO}_{2} \text { \{glass } \\
& 5 \mathrm{Ti}+3 \mathrm{SiO}_{2} \rightarrow \mathrm{Ti}_{5} \mathrm{Si}_{3}+3 \mathrm{O}_{2} \uparrow \\
& \mathrm{Cr}+3 / 2 \mathrm{Na}_{2} \mathrm{O} \rightarrow 1 / 2 \mathrm{Cr}_{2} \mathrm{O}_{3}+3 \mathrm{Na}(\mathrm{g}) \uparrow \\
& \mathrm{Cr}+1 / 2 \mathrm{SiO}_{2} \rightarrow \mathrm{CrO}+1 / 2 \mathrm{Si}
\end{aligned}
$$

If reactions [2] and [3] take place, the liberation of gas would form the bubbles observed in the overreacted samples. The bubbles and the brittle interfacial reaction layers result in weak coatings with poor adhesion to the metal. 
The adequate fabrication temperature for each coating is related to the temperature at which the glass softens and flows. The higher the softening point, the higher the temperature needed for the glass to flow. Consequently, the temperature limits of the different regions described in Figure 2 (lack of sintering, delamination, good adhesion and excessive interfacial reactions) are proportional to the silica content of the glass. For example, 6P68 coatings on Ti6Al4V should be fired for $30 \mathrm{~s}$ at $840^{\circ} \mathrm{C}$ in order to achieve the optimum adhesion, whereas, for the same firing time, $6 \mathrm{P} 57$ should be fired at $800^{\circ} \mathrm{C}$.

Figure 4. TEM image of the cross section of a 6 P57 glass coating on Ti6Al4V annealed at $800^{\circ} \mathrm{C}$ for $30 \mathrm{~min}$.

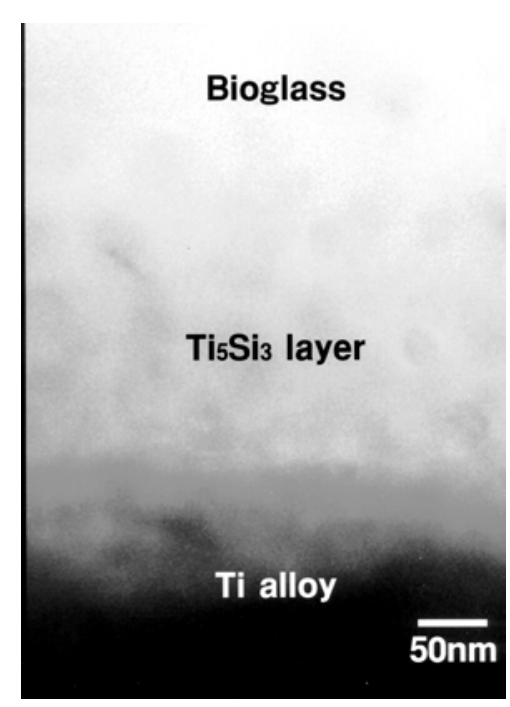

During in vitro testing in simulated body fluid, calcium phosphate crystals precipitated on the coatings with surface silica contents lower than $60 \mathrm{wt} \%$. Fourier Transform Infrared Spectromicroscopy (FTIRSM) and x-ray analysis of the precipitates identify them as apatite (Figure 5). The apatite grows in the form of oriented nanocrystals, with the c-axis perpendicular to the substrate. The EDS analysis indicates that the apatite crystals incorporate 1 to $5 \mathrm{wt} \% \mathrm{MgO}$ in their structure substituting for $\mathrm{CaO}$. The mechanism of apatite formation is similar to the one described by Hench for glasses in the $\mathrm{SiO}_{2}-\mathrm{CaO}-\mathrm{Na}_{2} \mathrm{O}-\mathrm{P}_{2} \mathrm{O}_{5}$ system. ${ }^{4}$ This involves the leaching of $\mathrm{CaO}, \mathrm{Na}_{2} \mathrm{O}$, and $\mathrm{P}_{2} \mathrm{O}_{5}$ and the formation of an amorphous calcium phosphate layer on which the apatite crystallizes. Coatings with silica content higher than $60 \mathrm{wt} \%$ did not form apatite but were more resistant to corrosion in SBF, their composition did not change even after soaking in simulated body fluid for 4 months.

The experiments have shown that there is a narrow range of glass compositions that can be used to coat Ti or Ti6Al4V and that also form apatite (the mineral component of the bone) during in vitro tests in simulated body fluid. 
Glasses with lower silica contents that readily form hydroxyapatite during in vitro testing in SBF can be prepared on Co-Cr. However, these coatings are not very resistant to corrosion and can crack during in vitro testing. Thus, one motivation for developing graded coatings is to reduce thermal stresses on the coatings on $\mathrm{Ti}$ and Ti6Al4V, so that a coating can be developed that has both a bioactive surface and an excellent adhesion to the metal. As an added advantage, the composition of the glass joining the metal can be such that its dissolution rate in body fluids is very limited (by using glasses with high $\mathrm{SiO}_{2}$ content), thus enhancing the longterm coating stability.
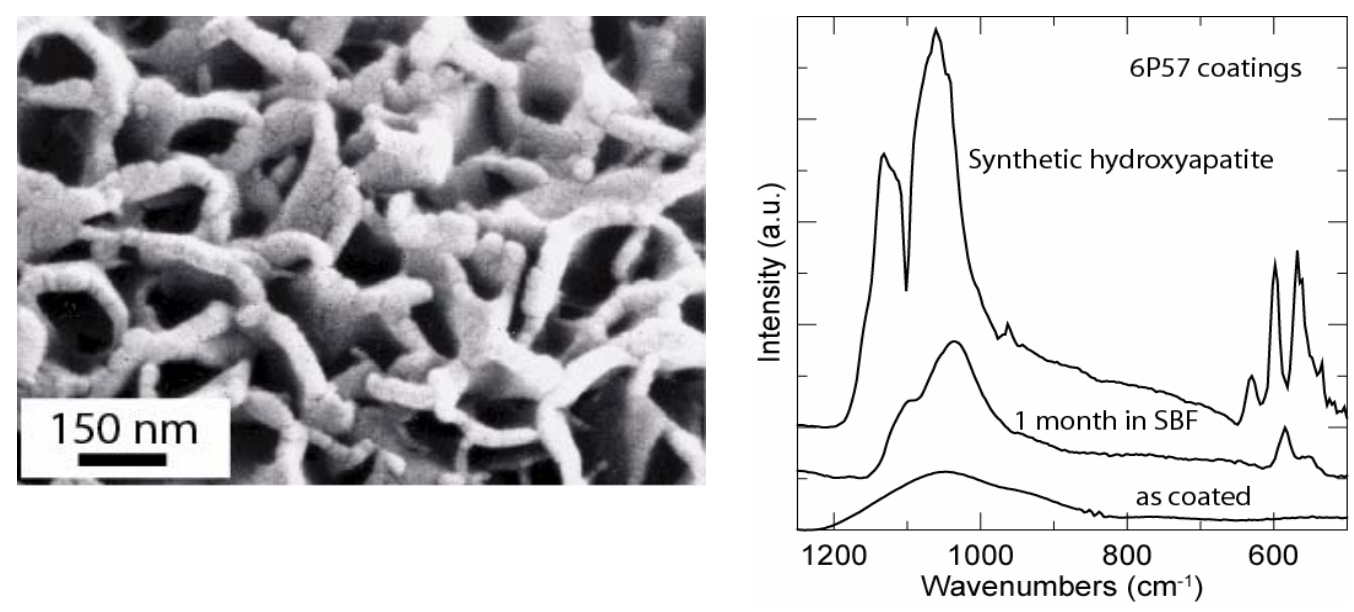

Figure 5. SEM micrographs and associated FTIRSM of the surface of a 6P57 coating on Ti6A14V after 1 month in SBF showing the precipitation of hydroxyapatite crystals.

The basic enameling technique developed in this work was modified to prepare graded coatings. Layers of glasses with different compositions and mixtures of glass and HA were sequentially deposited on the metal and then fastfired under the conditions that provide optimum adhesion for the glass in contact with the alloy. The elemental EDS analysis along the cross sections of multilayer coatings reveals a stepwise variation in the concentration of the glass components (with the exception of $\mathrm{Na}_{2} \mathrm{O}$ ) that corresponds to the composition of the different deposited glass layers (Figure 6). The concentration of $\mathrm{Na}_{2} \mathrm{O}$ varied gradually across the coating.

The control of the gradient development during firing is critical in the fabrication of layered coatings. Two mechanisms control the development of the gradient during heat treatment: interdiffusion of the glass components and infiltration of one glass layer into another. Infiltration between adjacent glass layers can occur as a result of the different softening points $\left(T_{\mathrm{s}}\right)$ of the glasses. 
Glasses with lower $\mathrm{SiO}_{2}$ soften at lower temperature and, consequently, may infiltrate (during heating) a neighboring layer with higher silica content (which remains porous). The EDS analysis indicates that because of the short firing times, infiltration and interdiffusion (with the exception of sodium) are limited to a few micrometers $(<5 \mu \mathrm{m})$. The diffusion coefficient of $\mathrm{Na}^{+1}$ in soda-limasilicate glasses ranges typically between $10^{-6}-10^{-7} \mathrm{~cm}^{2} / \mathrm{s}$ at temperatures between $800-900^{\circ} \mathrm{C}$ and is several orders of magnitude higher than for the other components. ${ }^{17}$ During firing, sodium interdiffusion is fast enough to generate a smooth $\mathrm{Na}_{2} \mathrm{O}$ profile even for the short firing times used in this work (Figure 6). The short firing times and low temperatures also allow the introduction of synthetic hydroxyapatite particles to improve bioactivity without any deleterious reaction. ${ }^{18}$

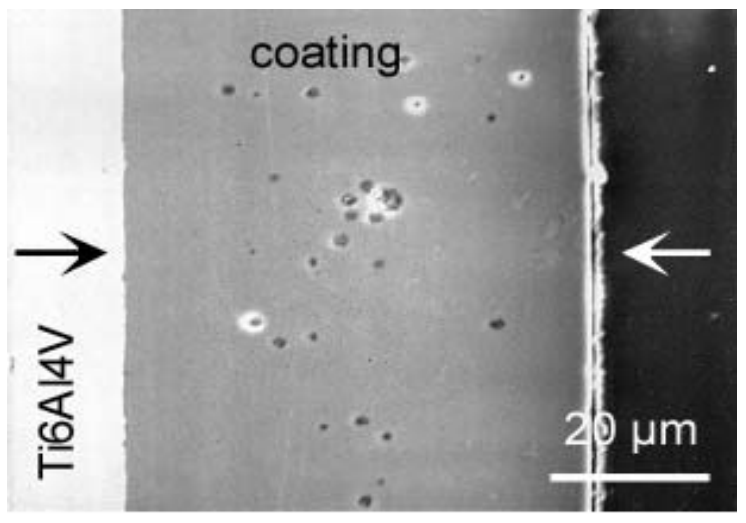

Figure 6. EDS elemental analysis along the cross section of a graded coating (6P61/6P55/6P53) on Ti6A14V.

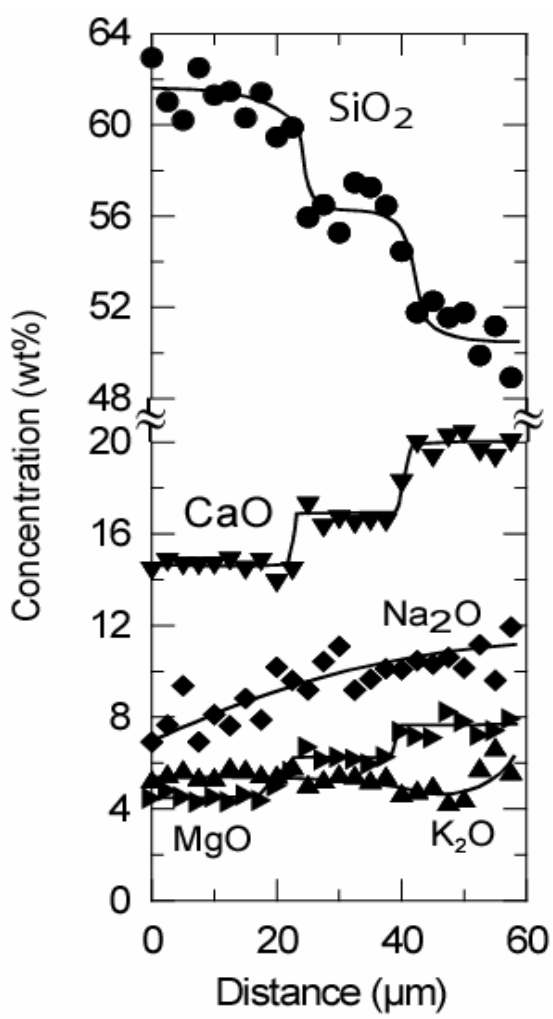

The low glass/metal thickness ratio of the coatings $(<1: 20)$ suggests that only a moderate relief of thermal stress on the external layer of multilayered coatings on Ti-based alloys should be expected using the graded approach. Nevertheless, for thin coatings, a gradient can markedly diminish the driving force for either cracking or delamination. In addition, stresses are singular where interfaces intersect the edges of samples, explaining why cracking originates at 
such places. These singularities are eliminated by continuous gradients; with multilayer coatings, the strength of these singularities is diminished inversely with the number of layers. ${ }^{19}$ The mechanical benefits of the graded approach allowed the preparation of layers on $\mathrm{Ti}$ and Ti6Al4V with lower silica content (which consequently made the layers more bioactive) or with glass/HA composites, maintaining strong adhesion at the glass/metal interface. Layers with silica content as low as $53 \mathrm{wt} \%$ or containing as much as $50 \mathrm{wt} \%$ of synthetic hydroxyapatite were successfully prepared using the multilayer method. Because of the thermal expansion mismatch and the resulting high thermal stresses generated during processing, all those layers cracked or delaminated when applied directly to the alloy.

One advantage of the graded coatings containing hydroxyapatite is that the HA particles act as nucleation centers for the precipitation of new apatite and the time required for apatite precipitation in vitro is reduced on average by half with respect to the times observed in single-layer glass coatings.

Figure 7. SEM micrograph of the cross section of a graded 6P61/6P50 coating on $\mathrm{Co}-\mathrm{Cr}$ (fired at $800^{\circ} \mathrm{C}$ for $30 \mathrm{~s}$ ) after 30 days in SBF.

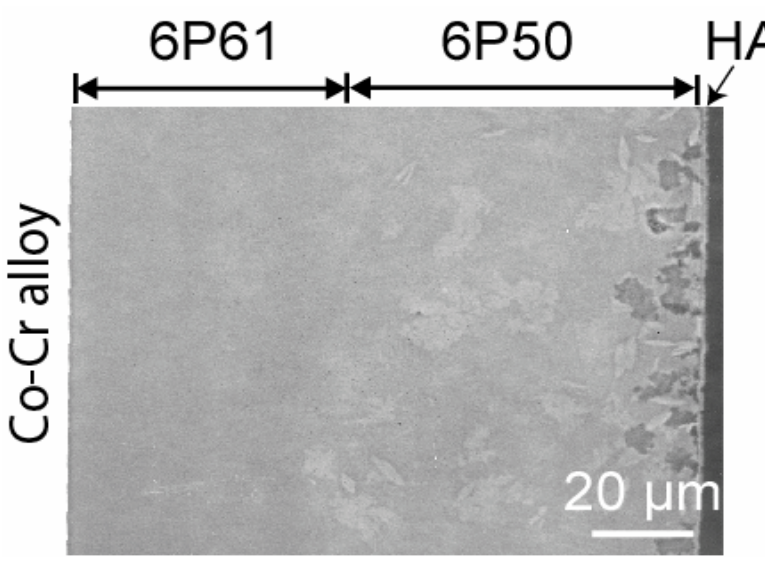

It is also possible to design gradients for which the residual stress distribution of the coating change from a surface under tension to a compressive stress for the glass in contact with the metal (using glasses in contact with the substrate with lower thermal expansion than the alloy). Recent theoretical and experimental studies have shown that such stress distributions are effective in arresting crack growth. ${ }^{20-21}$ In this way, coatings are more resistant to fatigue and can be fabricated with more reliable mechanical properties.

Owing to their low silica content, single-layer bioactive coatings are prone to corrosion. In some cases during in vitro tests, cracks grow in the coating, reaching the metal and initiating delamination. The multilayer coatings with high silica glasses in contact with the metal present excellent long-term stability during in vitro tests in simulated body fluid. Figure 7 shows a 6P61/6P50 bilayer coating 
on Co-Cr after 30 days in SBF. A thin layer of HA has precipitated on the coating surface whereas the 6P61 layer in contact with the metal remains unaltered providing good adhesion and protection of the alloy from the body fluid.

\section{CONCLUSIONS}

A new family of silicate-based glasses with composition tailored to match the thermal expansion coefficient of $\mathrm{Ti}$ and $\mathrm{Co}-\mathrm{Cr}$ based alloys has been developed to coat metallic implants, using a simple enameling technique. To better adjust the properties of the coating (in particular, to enhance bioactivity and increase chemical and mechanical stability) a multilayer approach has been used to fabricate graded glass coatings. Graded coatings with a corrosion-resistant glass composition protecting the metal and low surface silica contents were successfully fabricated. Also, layers containing as much as $50 \mathrm{wt} \%$ of synthetic hydroxyapatite were prepared with no appreciable degradation of the HA. The preliminary adhesion tests indicate a strong glass/metal bond, while at the same time the coatings form apatite on their surfaces when tested in vitro. The graded approach used in this work provides an exciting prospect for engineering new implant coatings.

\section{ACKNOWLEDGEMENTS}

This work was supported by the NIH/NIDCR grant 1R01DE11289. Jose M. Gomez-Vega wishes to thank the Spanish Ministry of Education (MEC) for financial support. S. Fujino wishes to thank the Japanese Ministry of Education, Culture and Sciences for a young researcher fellowship given to him in the National Program of Fellowships for young researchers in foreign countries, 2000. The Advanced Light Source is supported by the Director, Office of Science, Office of Basic Energy Sciences, Materials Sciences Division, of the U.S. Department of Energy under Contract No. DE-AC03-76SF00098 at Lawrence Berkeley National Laboratory.

\section{REFERENCES}

${ }^{1}$ M. Long and H.J. Rack, “Titanium Alloys in Total Joint Replacement-a Materials Science Perspective," Biomaterials, 19 1621-1639 (1998).

${ }^{2}$ A. M. Weinstein and A. J. T. Clemov, "Cobalt-based Alloys for Biomedical Applications"; pp. 441-447 in The Encyclopedia of Advanced Materials, vol. 1, D. Edited by Bloor, R. J. Brook, M. C. Flemings, and S. Mahajan. Pergamon, New York, 1994 
${ }^{3}$ Gerd Willmann, "Coating of Implants with Hydroxyapatite, Material Connections between Bone and Metal," Advanced Engineering Materials, 1[2], 95-105 (1999).

${ }^{4}$ L. L. Hench, "Bioceramics: From Concept to Clinic", J. Am. Ceram. Soc., 74 [7] 1487-1510 (1991).

${ }^{5}$ C. L. Tisdel, V. M. Goldberg, J. A. Parr, J. S. Bensusan, L. S. Staikoff, and S. Stevenson, "The Iinfluence of a Hydroxyapatite and Tricalcium-Phosphate Coating on Bone Growth into Titanium Fiber-Metal Implants," J. Bone Joint Surg. American Volume, 76A[2], 159-171 (1994).

${ }^{6}$ J. C. Chae, J. P. Collier, M. B. Mayor, V. A. Surprenant, and L. A. Dauphinais, "Enhanced Ingrowth of Porous-Coated CoCr Implants Plasma-Sprayed with Tricalcium Phosphate," Journal of Biomedical Materials Research, 26[1] 93-102 (1992).

${ }^{7}$ S. R. Radin and P. Ducheyne, "Plasma Spraying Induced Changes of Calcium Phosphate Ceramic Characteristics and the Effect on In Vitro Stability," Journal of Materials Science: Materials in Medicine, 3[1] 33-42 (1992).

${ }^{8}$ K. A. Gross, V. Gross, C. C. Berndt, "Thermal Analysis of Amorphous Phases in Hydroxyapatite Coatings," Journal of the American Ceramic Society, 81[1] 106112 (1998).

${ }^{9}$ W. R. Lacefield, "Hydroxylapatite Coatings"; pp. 223-238 in An Introduction to Bioceramics. Edited by L. L. Hench and J.Wilson, World Scientific, Singapore 1993.

${ }^{10}$ L. Hench and Ö. Anderson, "Bioactive Glass Coatings"; pp. 239-260 in An Introduction to Bioceramics, Edited by L. L. Hench and J.Wilson, World Scientific, Singapore 1993.

${ }^{11}$ M. Lee, E. Chang, B. C. Wang and C. Y. Yang, "Characteristics of Plasmasprayed bioactive glass coatings on Ti-6Al-4V alloy: An in vitro study," Surface and Coatings Technology, 79, 170-177 (1996).

${ }^{12}$ T. Kitsugi, T. Nakamura, M. Oka, Y. Senaha, T. Goto and T. Shibuya, "BoneBonding Behavior of Plasma-Sprayed Coatings of Bioglass ${ }^{\circledR}$, AW-Glass Ceramic, and Tricalcium Phosphate on Titanium Alloy," Journal of Biomedical Materials Research, 30, 261-269 (1996).

${ }^{13}$ J. H. Chern Lin, K. S. Chen and C. P. Ju, "Corrosion Behavior of Hydroxyapatite/Bioactive Glass Plasma Sprayed on Ti6A14V," Materials Chemistry and Physics, 41, 282-289 (1995). 
${ }^{14}$ I. W. Donald, "Review: Preparation, Properties and Chemistry of Glass and Glass-Ceramic-to-Metal Seals and Coatings," Journal of Materials Science, 28, 2841-2886 (1993).

${ }^{15}$ R. K. Brown and R. D. Watkins, "Reactions and bonding between glasses and titanium"; pp. 25-30 in Technology of Glass, Ceramic or Glass-Ceramic to Metal Sealing. Edited by W.E. Moddeman, C.W. Merten and D.P. Kramer, The American Society of Mechanical Engineers, New York, 1987.

${ }^{16}$ B. Kasemo and J. Gold, "Implant Surfaces and Interface Processes," Advanced Dental Research, 13 8-20 (1999).

${ }^{17}$ W. D. Kingery, H. K. Bowen and D. R. Uhlman, pp. 257-63 in Introduction to Ceramics, $2^{\text {nd }}$ Ed, John Wiley \& Sons, New York, 1976.

${ }^{18}$ A. Pazo, C. Santos, F. Guitian, A. P. Tomsia and J. S. Moya, "HA BioactiveGlass Composites - High Temperature Reactivity and In Vitro Behavior," Scripta Materialia, 34[11] 1729-1733 (1996).

${ }^{19}$ F. Erdogan, "Fracture Mechanics of Functionally Graded Materials," Composites Engineering, 5[7] 753-770 (1995).

${ }^{20}$ D.J. Green, R. Tandon and V. M. Sglavo, "Crack Arrest and Multiple Cracking in Glass Through the Use of Designed Residual Stress Profiles," Science, 283[5406] 1295-1297 (1999).

${ }^{21}$ J. F. Bartolome, J. S. Moya, J. Requena, J. LLorca and M. Anglada, "Fatigue Crack Growth Behavior in Mullite/Alumina Functionally Graded Ceramics," Journal of the American Ceramic Society, 81[6] 1502-1508 (1998). 